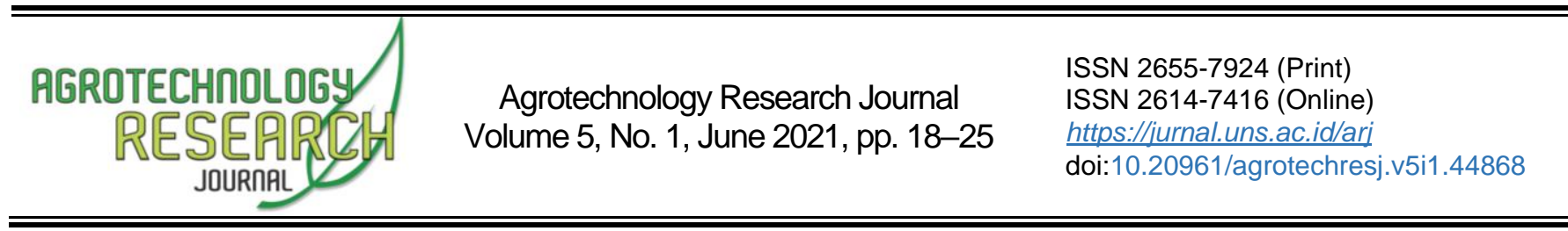

\title{
Karakter Perakaran Sejumlah Varietas Kopi Arabika pada Fase Bibit di Pesemaian
}

\section{Determining the Root Characteristics of Arabica Coffee Varieties in the Nursery Stage}

\author{
Ari Wibowo ${ }^{1 *}$ \\ ${ }^{1}$ Indonesian Coffee and Cocoa Research Institute, Jember, Jawa Timur, 68175, Indonesia
}

Received 15 October 2020; Accepted 04 March 2021; Published 30 June 2021

\begin{abstract}
Roots represent the fundamental structure and material transport systems in plants. These important organs are used to study the adaptation processes in the environment. During the nursery stage, root evaluation serves as determining the seedling quality before transplant. This research aims to ascertain the root characteristics of several Arabica coffee varieties for a suitably vigorous root nursery system. Kaliwining Experimental Garden, Jember, Indonesia, served as the research location. The method used was a completely randomized design with a single factor, including arabica coffee varieties (Abesinia-3, Andungsari-1, BLP-4, Gayo-1, K-08, K-29, K-34, K-79, K-130, Kartika-1, Kayumas and Sigararutang). The result showed that the differences in the various sample factors significantly influenced the root properties. In addition, the entire observation parameters demonstrated a positive correlation except for the root and shoot ratio. Furthermore, BLP-4 v obtained the maximum values for plant height, stem diameter, fresh dry weight of taproot, and root biomass, while Gayo-1 variety observed the greatest number of leaves. Also, the Sigararutang variety indicated the highest value of the fresh and dry weight of shoot, fresh weight of lateral roots, and root length, while Kayumas and K-34 varieties acquired the lowest values of plant height, fresh and dry weight of shoot and root, as well as root length. Therefore, BLP-4, Gayo-1, and Sigararutang varieties exhibited the potentials of broader adaptability.
\end{abstract}

Keywords: Morphological Aspect; Plant Biomass; Vigorous Variety

Cite this as (CSE Style): Wibowo A. 2021. Karakter perakaran beberapa varietas kopi Arabika pada fase bibit di pesemaian. Agrotechnology Res J. 5(1):18-25. https://dx.doi.org/10.20961/agrotechresj.v5i1.44868.

\section{PENDAHULUAN}

Kopi merupakan komoditas perkebunan primadona bagi Indonesia. Produksi kopi Indonesia masih menempati urutan keempat di dunia pada tahun 2018 (Wibowo 2019) dan tingkat konsumsi kopi dalam negeri menunjukkan tren positif pada kurun waktu yang sama. Perubahan iklim dan serangan hama penyakit menjadi tantangan bagi petani dalam meningkatkan produksi kopi rakyat (Gichimu et al. 2014; Wibowo 2019). Kopi Arabika mempunyai nilai ekonomi tinggi dan diminati oleh konsumen kopi dunia. Selama 5 tahun terakhir (2016 - 2020), harga kopi Arabika 43\% lebih tinggi dari kopi Robusta (Plecher 2020), sehingga berpotensi untuk terus dikembangkan. Pertanaman kopi Arabika di Indonesia tersebar luas dari Pulau Sumatera hingga Papua. Bahan tanam unggul yang mempunyai daya adaptasi luas dapat menunjang peningkatan produksi

${ }^{*}$ Corresponding Author:

E-Mail: ariwibowo.iccri@gmail.com kopi nasional. Untuk menemukan varietas kopi yang mempunyai adaptasi luas, salah satu karakter yang dapat diamati adalah akar tanaman (Kakanga et al. 2017; Erdiansyah et al. 2019).

Sistem perakaran tanaman kopi dewasa terbagi menjadi 5 tipe, yaitu (i) bagian akar pusat (center taproots), berkembang secara vertikal dari pangkal akar dan berakhir pada kedalaman 0,45 - 1 meter; (ii) akar aksial (axial roots), dapat menembus kedalaman tanah mencapai $3 \mathrm{~m}$ dan percabangan akarnya menyebar ke segala arah; (iii) akar lateral, tumbuh secara mendatar dan biasanya dekat dengan permukaan tanah (berjarak 1,2 - 1,8 $\mathrm{m}$ dari batang tanaman); (iv) serabut akar, mempunyai panjang yang bervariasi dan tersebar di akar pangkal, akar aksial, dan akar lateral; (v) rambut akar, berfungsi sebagai penyedia unsur hara dan mineral bagi tanaman kopi, berjumlah banyak dan tersebar dari kedalaman tanah sampai permukaan tanah (Wintgens 2004). Akar tanaman kopi dapat menembus jauh ke dalam tanah (Defrenet et al. 2016), meskipun sekitar $90 \%$ perakarannya hanya berkembang di lapisan tanah bagian atas (kedalaman $30-50 \mathrm{~cm}$ ) (Kufa dan 
Burkhardt 2013; Vicente et al. 2017). Kopi Arabika mempunyai persebaran akar yang lebih luas dan perakaran yang lebih panjang dibandingkan kopi Robusta (Partelli et al. 2020).

Evaluasi yang dilakukan pada struktur akar dapat menjadi acuan dalam mempelajari proses adaptasi tanaman terhadap perubahan iklim (Defrenet et al. 2016; Sakai et al. 2015) dan sebagai pedoman melakukan proses seleksi berdasarkan karakter perakaran tanaman yang unggul (Parwata et al. 2017; Torey et al. 2013). Gaiser et al. (2013) mengungkapkan bahwa tanaman dengan vigoritas tinggi akan mempunyai struktur perakaran yang kuat. Meski demikian, perkembangan akar sangat dipengaruhi oleh jenis media tempat tanam (Gaiser et al. 2013; Silva et al. 2016) dan genetik tanaman (Dahlan et al. 2009; Betegon-Putze et al. 2019). Parameter panjang akar dan volume akar merupakan karakter penting yang harus diamati (Himmelbauer et al. 2004; Gaiser et al. 2013; Delory et al. 2017) untuk mengetahui potensi penyerapan air dan unsur hara. Parameter kunci lain dalam sistem perakaran adalah bobot akar, volume akar, rasio akar : pucuk, panjang akar spesifik, pola sebaran akar, kerapatan rambut akar, kemampuan serapan, dan viabilitas akar (Andarini et al. 2017; Judd et al. 2015). Varietas kopi dengan daya adaptasi luas memiliki sistem perakaran kuat karena organ akar akan memberikan respons pertama saat terjadi cekaman baik biotik atau abiotik akibat dampak dari perubahan iklim (Kufa dan Burkhardt 2013; Defrenet et al. 2016).

Kajian tentang karakter morfologi perakaran tanaman kopi Arabika di Indonesia masih terbatas. Oleh karena itu, hasil penelitian ini akan memberikan informasi tentang aspek morfologi akar dari beberapa varietas kopi Arabika. Adanya informasi pengetahuan tentang karakter perakaran tanaman berbagai varietas kopi Arabika dapat menjadi metode pendekatan untuk melakukan seleksi varietas kopi yang mempunyai daya adaptasi luas. Semakin kuat karakter perakaran tanaman maka semakin luas daya adaptasinya. Penelitian ini bertujuan untuk mengetahui dan menyeleksi perakaran tanaman kopi Arabika yang mempunyai perakaran kuat pada fase bibit dari beberapa varietas.

\section{BAHAN DAN METODE}

Benih kopi yang disemai merupakan benih koleksi yang dipanen pada musim panen Agustus 2019. Penyemaian benih dilaksanakan pada bulan Desember 2019 - Mei 2020 di rumah kaca Kebun Percobaan Kaliwining Pusat Penelitian Kopi dan Kakao Indonesia, Jember, Jawa Timur. Kebun percobaan tersebut terletak pada ketinggian \pm 62 mdpl dengan suhu udara pagi dan siang hari $\pm 28^{\circ} \mathrm{C}$ dan sore hari $\pm 30^{\circ} \mathrm{C}$ serta kelembaban relatif udara berkisar antara 55\% - 70\%.

Bahan penelitian berupa benih kopi dari 12 varietas kopi Arabika koleksi dari Laboratorium Pemuliaan Tanaman, yaitu Abesinia-3, Andungsari-1, BLP-4, Gayo1, K-08, K-29, K-34, K-79, K-130, Kartika-1, Kayumas, dan Sigararutang. Rancangan penelitian menggunakan Rancangan Acak Lengkap satu faktor (varietas) dengan ulangan sebanyak 5 kali. Benih dari masing-masing varietas dikupas kulit tanduknya dan direndam dalam larutan fungisida $0,2 \%$ (b : v) selama 3 malam. Benih kemudian ditiriskan dan disemai pada bak pesemaian berukuran $40 \times 30 \times 15 \mathrm{~cm}$ dengan media pasir selama 2 bulan. Setelah memasuki fase kepelan, bibit kopi kemudian dipindahkan ke dalam gelas plastik bervolume $400 \mathrm{ml}$ yang telah berisi media pasir dan tanah (komposisi 2:1). Bibit dirawat sesuai dengan standar pemeliharaan bibit kopi. Setelah berumur 4 bulan, bibit kemudian dipanen dan diamati.

Variabel pengamatan saat panen bibit meliputi sebagai berikut:

1. Tinggi tanaman, diukur menggunakan penggaris dari pangkal batang sampai titik tumbuh bibit.

2. Diameter batang, diukur menggunakan jangka sorong digital pada ketinggian $\pm 2 \mathrm{~cm}$ dari pangkal batang bibit.

3. Jumlah daun, dihitung dari daun yang telah membuka penuh dan daun kepel tidak dihitung.

4. Panjang akar, diukur menggunakan penggaris dari tautan batang dan akar sampai ujung akar.

5. Bobot segar dan bobot kering pucuk yang dihitung menggunakan timbangan digital dengan tingkat ketelitian dua angka di belakang koma.

6. Bobot segar dan bobot kering akar tunggang yang dihitung menggunakan timbangan digital dengan tingkat ketelitian empat angka di belakang koma.

7. Bobot segar dan bobot kering akar lateral yang dihitung menggunakan timbangan digital dengan tingkat ketelitian empat angka di belakang koma.

8. Biomassa akar merupakan bobot total akar tanaman kering (bobot akar tunggang dan akar lateral kering).

9. Nisbah akar pucuk merupakan perbandingan bobot total akar kering dan pucuk kering.

Data diolah menggunakan analisis varian (ANOVA) dan Uji Jarak Berganda Duncan dengan tingkat kepercayaan 95\% pada perangkat lunak SAS 9.0.

\section{HASIL DAN PEMBAHASAN \\ Karakter pertumbuhan bibit}

Hasil penelitian (Tabel 1) menunjukkan varietas BLP4 mempunyai nilai tinggi tanaman tertinggi yaitu sebesar $15,62 \mathrm{~cm}$. Tinggi tanaman varietas BLP-4 signifikan lebih tinggi dari varietas Abesinia-3, Andungsari-1, K-08, K29, K-34, K-79, K-130, Kartika-1, Kayumas, dan Sigararutang. Varietas Gayo-1 mempunyai tinggi tanaman sebesar $13,48 \mathrm{~cm}$ dan tidak berbeda nyata dengan varietas BLP-4. Varietas K-34 dan Kayumas mempunyai tinggi tanaman terendah, yaitu $6,47 \mathrm{~cm}$ dan $6,50 \mathrm{~cm}$.

Perkembangan diameter batang terbesar dimiliki oleh varietas BLP-4, yaitu 1,91 mm. Diameter batang terkecil dimiliki oleh varietas K-34 dan Kayumas, yaitu sebesar 1,32 mm. Varietas BLP-4 mempunyai diameter batang nyata lebih besar dari varietas Andungsari-1, K-34, K-79, $\mathrm{K}-130$, dan Kayumas. Jumlah daun terbanyak dimiliki oleh varietas Gayo-1, yaitu sebanyak 9 helai daun. Jumlah daun ini tidak berbeda nyata dengan jumlah 
daun varietas Abesinia-3, BLP-4, K-08, K-29, K-79, K130, Kartika-1, dan Sigararutang. Varietas Kayumas mempunyai jumlah daun paling sedikit sebanyak 5 helai daun. Rerata jumlah daun bibit kopi Arabika berumur 4 bulan setelah pindah tanam berkisar antara $6-10$ helai daun.

Bobot segar dan bobot kering pucuk terbesar dimiliki oleh varietas Sigararutang yaitu sebesar 4,35 g dan 1,18 g. Nilai kedua parameter tersebut signifikan lebih besar dari bobot segar dan bobot kering varietas Abesinia-3, Andungsari-1, Gayo-1, K-08, K-29, K-34, K-79, K-130, Kartika-1, dan Kayumas. Varietas BLP-4 mempunyai bobot segar dan bobot kering pucuk sebesar 3,58 $\mathrm{g}$ dan 1,09. Nilai tersebut tidak berbeda nyata dengan bobot segar dan bobot kering varietas Sigararutang. Kayumas mempunyai bobot segar dan bobot kering pucuk paling kecil, yaitu $1,15 \mathrm{~g}$ dan 0,22 $\mathrm{g}$.

Berdasarkan nilai tinggi tanaman, diameter batang, dan jumlah daun, varietas BLP-4, Gayo-1, dan Sigararutang merupakan tiga varietas yang mempunyai pertumbuhan paling tinggi. Karakter tinggi tanaman merupakan indikator pertumbuhan tanaman dan dapat dipengaruhi oleh lingkungan (Anasari et al. 2017). Nilai tinggi tanaman berkorelasi positif dengan jumlah daun (Syahadat and Aziz 2013). Hasil yang sama didapatkan dalam penelitian ini (Tabel 1). Semakin tinggi nilai tinggi tanaman maka jumlah daun juga semakin banyak. Pertumbuhan tinggi bibit, diameter batang, dan jumlah daun dipengaruhi oleh perkembangan akar. Tanaman dengan pertumbuhan kuat akan dipilih sebagai bahan pengujian selanjutnya. Gichimu et al. (2014) mengungkapkan bahwa bibit kopi yang tercekam kekeringan akan memberikan respons penurunan pada tinggi tanaman, jumlah daun, dan jumlah ruas batang.
Varietas Sigararutang, BLP-4, K-29, dan Gayo-1 merupakan empat varietas kopi Arabika yang mempunyai bobot segar dan bobot kering pucuk tertinggi. Menurut Lewu dan Killa (2020), bobot kering tanaman menggambarkan penimbunan bersih asimilasi $\mathrm{CO}_{2}$ yang dilakukan selama pertumbuhan dan perkembangan tanaman sehingga dapat menjadi indikator pertumbuhan suatu tanaman. Varietas Sigrarutang, BLP-4, K-29, dan Gayo-1 mempunyai bobot kering tertinggi sehingga keempat varietas tersebut mempunyai pertumbuhan bibit lebih baik dari varietasvarietas yang lain.

Hasil analisis menunjukkan bahwa perbedaan varietas berpengaruh terhadap karakter pertumbuhan tanaman. Karakter morfologi merupakan hasil interaksi antara faktor genetik dan lingkungan sehingga setiap varietas kopi Arabika yang diuji dapat menampilkan nilai pertumbuhan yang berbeda-beda. Menurut da Rosa et al. (2010), perkecambahan benih kopi dipengaruhi oleh jenis genotipe kopi. Adanya variasi genetik ini dalam bidang pemuliaan tanaman dapat dijadikan sebagai dasar melakukan seleksi karena setiap genotipe dapat menampilkan ekspresi gen yang berbeda-beda.

Varietas Sigararutang, BLP-4, K-29, dan Gayo-1 merupakan empat varietas kopi Arabika yang mempunyai bobot segar dan bobot kering pucuk tertinggi. Bobot kering tanaman menggambarkan penimbunan bersih asimilasi $\mathrm{CO}_{2}$ yang dilakukan selama pertumbuhan dan perkembangan tanaman sehingga dapat menjadi indikator pertumbuhan suatu tanaman (Lewu dan Killa 2020). Varietas Sigararutang, BLP-4, K29, dan Gayo-1 mempunyai bobot kering tertinggi sehingga keempat varietas tersebut mempunyai pertumbuhan bibit lebih baik dari varietas-varietas yang lain.

Tabel 1. Pertumbuhan pucuk dan bobot pucuk

\begin{tabular}{lccccc}
\hline Varietas & Tinggi Tanaman $(\mathrm{cm})$ & Diameter Batang $(\mathrm{mm})$ & Jumlah Daun & $\begin{array}{c}\text { Bobot Segar } \\
\text { pucuk }(\mathrm{g})\end{array}$ & $\begin{array}{c}\text { Bobot Kering } \\
\text { pucuk }(\mathrm{g})\end{array}$ \\
\hline Abesinia-3 & $10,28 \mathrm{~cd}$ & $1,60 \mathrm{abc}$ & $7,20 \mathrm{abc}$ & $1,79 \mathrm{de}$ & $0,54 \mathrm{ef}$ \\
Andungsari-1 & $10,10 \mathrm{~cd}$ & $1,56 \mathrm{bc}$ & $7,14 \mathrm{bc}$ & $2,08 \mathrm{de}$ & $0,60 \mathrm{de}$ \\
BLP-4 & $15,62 \mathrm{a}$ & $1,91 \mathrm{a}$ & $8,50 \mathrm{ab}$ & $3,58 \mathrm{ab}$ & $1,09 \mathrm{ab}$ \\
Gayo-1 & $13,48 \mathrm{ab}$ & $1,65 \mathrm{ab}$ & $9,13 \mathrm{a}$ & $3,12 \mathrm{bc}$ & $0,84 \mathrm{~cd}$ \\
K-08 & $7,78 \mathrm{def}$ & $1,60 \mathrm{abc}$ & $8,00 \mathrm{abc}$ & $2,38 \mathrm{~cd}$ & $0,67 \mathrm{cde}$ \\
K-29 & $9,95 \mathrm{~cd}$ & $1,67 \mathrm{ab}$ & $8,75 \mathrm{ab}$ & $3,18 \mathrm{bc}$ & $0,89 \mathrm{bc}$ \\
K-34 & $6,47 \mathrm{f}$ & $1,32 \mathrm{c}$ & $6,29 \mathrm{~cd}$ & $1,18 \mathrm{e}$ & $0,32 \mathrm{fg}$ \\
K-79 & $8,51 \mathrm{def}$ & $1,56 \mathrm{bc}$ & $8,67 \mathrm{ab}$ & $2,27 \mathrm{~cd}$ & $0,65 \mathrm{cde}$ \\
K-130 & $7,36 \mathrm{ef}$ & $1,46 \mathrm{bc}$ & $7,88 \mathrm{abc}$ & $2,02 \mathrm{de}$ & $0,55 \mathrm{ef}$ \\
Kartika-1 & $9,39 \mathrm{cde}$ & $1,61 \mathrm{abc}$ & $7,25 \mathrm{abc}$ & $2,74 \mathrm{bcd}$ & $0,77 \mathrm{cde}$ \\
Kayumas & $6,50 \mathrm{f}$ & $1,32 \mathrm{c}$ & $5,33 \mathrm{~d}$ & $1,15 \mathrm{e}$ & $0,22 \mathrm{~g}$ \\
Sigararutang & $11,63 \mathrm{bc}$ & $1,65 \mathrm{ab}$ & $9,00 \mathrm{ab}$ & $4,35 \mathrm{a}$ & $1,18 \mathrm{a}$ \\
\hline
\end{tabular}

Keterangan: Angka yang diikuti oleh huruf yang berbeda pada kolom yang sama menunjukkan hasil yang berbeda nyata menurut Uji Jarak Berganda Duncan taraf 5\%. 
Hasil analisis menunjukkan bahwa perbedaan varietas berpengaruh terhadap karakter pertumbuhan tanaman $(p<0,05)$. Karakter morfologi merupakan hasil interaksi antara faktor genetik dan lingkungan sehingga setiap varietas kopi Arabika yang diuji dapat menampilkan nilai pertumbuhan akar yang berbedabeda. Faktor genetik dapat berpengaruh terhadap pertumbuhan perakaran tanaman (Betegon-Putze et al. 2019; Parwata et al. 2017; Vicente et al. 2017).

\section{Keragaan karakter perakaran bibit kopi Arabika Bobot segar, bobot kering, dan panjang akar}

Hasil analisis menunjukkan bahwa varietas BLP-4 mempunyai bobot segar dan bobot kering akar tunggang nyata lebih besar dari varietas kopi Arabika yang diuji, yaitu sebesar $0,30 \mathrm{~g}$ dan 0,12 g. Bobot segar akar tunggang terendah dimiliki oleh varietas Kayumas dan bobot kering akar tunggang terendah dimiliki oleh varietas K-34 (Tabel 2). Sepuluh dari dua belas varietas kopi Arabika yang diuji mempunyai nilai bobot segar dan bobot kering akar tunggang yang merata karena hasil analisis menunjukkan tidak beda nyata. Selisih nilai rerata antar varietas pada kedua parameter tersebut hanya kecil.

Nilai bobot segar akar lateral bibit kopi Arabika berkisar antara 0,10 g - 0,75 g sedangkan nilai bobot kering akar lateral berkisar antara 0,01 g - 0,08 g. Varietas Sigararutang mempunyai bobot segar akar lateral terberat dan bobot segar akar lateral terendah dimiliki oleh varietas Kayumas. Varietas K-29 mempunyai bobot kering akar lateral tertinggi dan varietas K-34 dan Kayumas mempunyai bobot kering akar lateral nyata lebih rendah dari varietas kopi yang lain (Tabel 2). Perkembangan akar lateral terbaik dimiliki oleh varietas Gayo-1, K-29, dan BLP-4 karena nilai bobot segar dan bobot kering akar lateral ketiga varietas tersebut lebih tinggi dibanding varietas yang lain. Akar lateral pada tanaman kopi tumbuh dan berkembang secara horizontal dan menyebar di sekitar permukaan tanah.

Akar lateral kopi pada fase perkecambahan akan muncul pada hari ke-15 - 20 tergantung tipe dan jenis kopinya (da Rosa et al. 2010). Akar lateral akan muncul di sekitar persimpangan antara hipokotil dan akar primer. Di periode yang sama, rambut-rambut akar juga akan muncul pada permukaan akar primer. Akar lateral akan banyak dijumpai pada kedalaman tanah sekitar 1,2 - 1,8 m pada tanaman dewasa (Wintgens 2004) dan jumlahnya tergantung kelas umur tanaman kopi (Silva et al. 2016). Bobot akar merupakan indikasi efektivitas penyerapan unsur hara dan air oleh tanaman. Tanaman dengan bobot akar lebih besar mempunyai kemampuan menyerap air dan unsur hara lebih banyak sehingga dapat mendukung pertumbuhan tajuk tanaman, begitu juga sebaliknya.

Varietas Sigararutang mempunyai perkembangan akar terpanjang sedangkan varietas K-34 mempunyai akar nyata lebih pendek diantara varietas kopi Arabika yang lain. Panjang akar primer tanaman varietas BLP-4, Gayo-1, dan Kartika-1 tidak berbeda nyata dengan varietas Sigararutang sehingga pertumbuhan akar ketiga varietas tersebut juga termasuk baik. Selain varietas K-34, varietas lain yang mempunyai akar primer lebih pendek adalah varietas Andungsari-1 dan Kayumas (Tabel 2).

Varietas kopi Sigararutang yang mempunyai perakaran kuat (panjang akar 11,82 cm; bobot segar akar 0,97 g; bobot kering akar 0,15 g) juga mempunyai pertumbuhan tajuk lebih besar dari varietas yang lain (tinggi tanaman 11,63 cm; jumlah daun 9 helai; bobot segar pucuk 4,35 g; bobot kering pucuk 1,18 g).

Tabel 2. Karakter perakaran pada bibit kopi Arabika

\begin{tabular}{lccccc}
\hline Varietas & $\begin{array}{c}\text { Bobot Akar } \\
\text { Tunggang Basah } \\
(\mathrm{g})\end{array}$ & $\begin{array}{c}\text { Bobot Akar } \\
\text { Tunggang Kering } \\
(\mathrm{g})\end{array}$ & $\begin{array}{c}\text { Bobot } \\
\text { Akar Lateral } \\
\text { Segar }(\mathrm{g})\end{array}$ & $\begin{array}{c}\text { Bobot } \\
\text { Akar Lateral } \\
\text { Kering }(\mathrm{g})\end{array}$ & $\begin{array}{c}\text { Panjang Akar } \\
(\mathrm{cm})\end{array}$ \\
\hline Abesinia-3 & $0,14 \mathrm{bcd}$ & $0,05 \mathrm{bcd}$ & $0,16 \mathrm{def}$ & $0,02 \mathrm{de}$ & $8,30 \mathrm{cde}$ \\
Andungsari-1 & $0,16 \mathrm{bc}$ & $0,05 \mathrm{bcd}$ & $0,25 \mathrm{cdef}$ & $0,03 \mathrm{cde}$ & $6,80 \mathrm{ef}$ \\
BLP-4 & $0,30 \mathrm{a}$ & $0,12 \mathrm{a}$ & $0,39 \mathrm{bc}$ & $0,06 \mathrm{abc}$ & $10,88 \mathrm{abc}$ \\
Gayo-1 & $0,19 \mathrm{bc}$ & $0,06 \mathrm{bcd}$ & $0,57 \mathrm{abc}$ & $0,05 \mathrm{abcd}$ & $11,36 \mathrm{ab}$ \\
\hline K-08 & $0,15 \mathrm{bcd}$ & $0,05 \mathrm{bcd}$ & $0,33 \mathrm{bcd}$ & $0,04 \mathrm{bcd}$ & $7,60 \mathrm{de}$ \\
K-29 & $0,20 \mathrm{bc}$ & $0,07 \mathrm{bc}$ & $0,62 \mathrm{ab}$ & $0,08 \mathrm{a}$ & $8,70 \mathrm{bcde}$ \\
K-34 & $0,12 \mathrm{~cd}$ & $0,03 \mathrm{~d}$ & $0,11 \mathrm{ef}$ & $0,01 \mathrm{e}$ & $4,22 \mathrm{f}$ \\
K-79 & $0,14 \mathrm{bcd}$ & $0,05 \mathrm{bcd}$ & $0,33 \mathrm{bcd}$ & $0,03 \mathrm{cde}$ & $7,70 \mathrm{de}$ \\
K-130 & $0,16 \mathrm{bc}$ & $0,04 \mathrm{~cd}$ & $0,30 \mathrm{cde}$ & $0,03 \mathrm{cde}$ & $8,60 \mathrm{bcde}$ \\
Kartika-1 & $0,21 \mathrm{~b}$ & $0,07 \mathrm{bc}$ & $0,37 \mathrm{bcd}$ & $0,05 \mathrm{abcd}$ & $9,72 \mathrm{abcd}$ \\
Kayumas & $0,08 \mathrm{~d}$ & $0,05 \mathrm{bcd}$ & $0,10 \mathrm{f}$ & $0,01 \mathrm{e}$ & $6,23 \mathrm{ef}$ \\
Sigararutang & $0,22 \mathrm{~b}$ & $0,08 \mathrm{~b}$ & $0,75 \mathrm{a}$ & $0,07 \mathrm{ab}$ & $11,82 \mathrm{a}$ \\
\hline
\end{tabular}

Keterangan: Angka yang diikuti oleh huruf yang berbeda pada kolom yang sama menunjukkan hasil yang berbeda nyata menurut Uji Jarak Berganda Duncan taraf 5\%. 
Akar akan merespons lebih awal jika terjadi perubahan kondisi pada lingkungan tempat tanam. Perkembangan akar yang baik akan mendukung pertumbuhan tanaman, pembentukan biomassa, dan ketahanan tanaman terhadap cekaman lingkungan (Sakai et al. 2015; Zakariyya 2017). Sistem perakaran yang kuat menjadi kriteria utama dalam melakukan seleksi tanaman untuk daerah adaptasi yang luas. Pengujian karakter akar juga dilakukan oleh Gichimu et al. (2014) dan Erdiansyah et al. (2019) pada pembibitan kopi untuk mengetahui karakter akar kopi yang dapat beradaptasi terhadap cekaman kekeringan.

Varietas BLP-4, Gayo-1, Kartika-1, dan Sigararutang mempunyai panjang akar berkisar antara $9,72 \mathrm{~cm}-$ $11,82 \mathrm{~cm}$ (Tabel 2). Nilai panjang akar keempat varietas tersebut lebih besar daripada varietas kopi Arabika yang lain. Bobot segar dan bobot kering akar keempat varietas juga menunjukkan nilai yang tidak berbeda nyata. Akar merupakan sensor awal bagi tanaman dalam merespons kondisi lingkungan tempat tumbuh (Silveira et al. 2014; Rodriguez et al. 2017). Tanaman kopi yang tercekam kekeringan mempunyai akar lebih panjang dan perakaran yang kuat (Gichimu et al. 2014) serta organ akar akan mendapat alokasi biomassa lebih besar daripada tajuk.

\section{Biomassa akar dan nisbah akar pucuk}

Nilai biomassa akar terbesar dimiliki oleh varietas BLP-4 $(0,18 \mathrm{~g})$ sedangkan varietas K-34 $(0,04 \mathrm{~g})$ dan Kayumas $(0,06 \mathrm{~g})$ mempunyai nilai biomassa akar terkecil. Varietas Kayumas mempunyai nisbah akar pucuk tertinggi, yaitu 0,19 sedangkan varietas $\mathrm{K}-79$ mempunyai nisbah akar pucuk terendah, yaitu 0,11 (Tabel 3). Nisbah akar pucuk merupakan nilai perbandingan antara bobot kering akar dan bobot kering pucuk (pucuk) (Kakanga et al. 2017). Nilai nisbah akar pucuk yang tinggi menunjukkan pertumbuhan akar lebih bagus daripada pertumbuhan pucuknya.

Varietas Kayumas mempunyai nisbah akar pucuk lebih tinggi namun nilai biomassa akar dan panjang akarnya lebih rendah daripada varietas kopi yang lain. Apabila nilai nisbah akar dan tajuk mendekati 1 maka pertumbuhan akar dan tajuk tanaman seimbang. Pada kondisi cekaman abiotik, genotipe tanaman tahan biasanya memberikan respons perakaran yang lebih peka. Alokasi biomassa lebih besar ditujukan pada akar karena organ ini akan berusaha mencari unsur hara sebagai upaya penyesuaian terhadap lingkungan yang tidak sesuai dengan habitatnya (Gichimu et al. 2014).

Mutu morfologis bibit dapat diamati melalui dua variabel, yaitu nisbah pucuk akar dan biomassa akar bibit sebagai indikator kemampuan hidup dan pertumbuhan tanaman. Nisbah pucuk akar yang rendah menunjukkan daya hidup dan adaptasi tumbuhan yang lebih tinggi (Andarini et al. 2017; Komala dan Kuwato 2008). Bibit tanaman akan mempunyai mutu morfologis baik apabila nisbah akar pucuknya tinggi dan biomassa akarnya lebih besar. Varietas BLP-4, K-29, dan Sigararutang mempunyai biomassa akar $(0,18 \mathrm{~g} ; 0,15 \mathrm{~g}$;
$0,16 \mathrm{~g})$ dan nisbah akar pucuk $(0,17 ; 0,17 ; 0,13)$ cukup besar.

Varietas BLP-4 dan Sigararutang mempunyai biomassa pucuk dan akar yang tertinggi sehingga pertumbuhan kedua varietas ini cukup baik di fase pembibitan. Nilai biomassa tanaman yang terendah dimiliki oleh varietas K-34 dan Kayumas. Hasil analisis menunjukkan bahwa karakter pertumbuhan (tinggi tanaman, diameter batang, jumlah daun, bobot segar dan bobot kering pucuk berkorelasi positif dengan karakter perakaran (bobot segar dan kering akar tunggang, bobot segar dan kering akar lateral, panjang akar, biomassa akar) (Tabel 4). Semakin kuat perakaran tanaman maka pertumbuhan tajuk semakin baik. Akar merupakan penunjang dalam perkembangan tajuk tanaman.

Setiap varietas kopi Arabika menunjukkan karakter akar yang berbeda-beda. Tanaman dewasa varietas Abesinia-3, BLP-4, Gayo-1, dan Kayumas tumbuh lebih tinggi (jagur) dan berdaun lebih lebar dibandingkan dengan varietas Andungsari-1, K-08, K-29, K-34, K-130, Kartika-1 dan Sigararutang. Pada parameter tinggi tanaman, jumlah daun, dan panjang akar, varietas BLP4, Gayo-1, dan Sigararutang selalu mempunyai nilai pengamatan yang menempati urutan tertinggi. Varietas BLP-4 merupakan kopi Arabika yang berasal dari Blawan Pasumah di dataran tinggi ljen, Jawa Timur. Varietas Sigararutang merupakan varietas anjuran kopi Arabika hasil pemuliaan partisipatif yang berasal dari dataran tinggi di Tapanuli Utara, Sumatera Utara. Varietas Gayo-1 merupakan varietas anjuran hasil pemuliaan partisipatif yang berasal dari dataran tinggi Gayo di Aceh. Ketiga varietas tersebut berasal dari tiga tempat yang berbeda sehingga pertumbuhan tajuk dan perkembangan akar bibit tanaman tersebut juga berbeda-beda.

Tabel 3. Biomassa akar dan nisbah akar pucuk bibit

\begin{tabular}{lll}
\hline Varietas & $\begin{array}{c}\text { Biomassa } \\
\text { Akar }(\mathrm{g})\end{array}$ & $\begin{array}{c}\text { Nisbah Akar dan } \\
\text { Pucuk }\end{array}$ \\
\hline Abesinia-3 & $0,07 \mathrm{cde}$ & $0,13 \mathrm{abc}$ \\
Andungsari-1 & $0,08 \mathrm{cde}$ & $0,13 \mathrm{abc}$ \\
BLP-4 & $0,18 \mathrm{a}$ & $0,17 \mathrm{ab}$ \\
Gayo-1 & $0,10 \mathrm{bcd}$ & $0,13 \mathrm{abc}$ \\
K-08 & $0,09 \mathrm{cde}$ & $0,12 \mathrm{bc}$ \\
K-29 & $0,15 \mathrm{ab}$ & $0,17 \mathrm{ab}$ \\
K-34 & $0,04 \mathrm{e}$ & $0,15 \mathrm{abc}$ \\
K-79 & $0,07 \mathrm{cde}$ & $0,11 \mathrm{c}$ \\
K-130 & $0,08 \mathrm{cde}$ & $0,14 \mathrm{abc}$ \\
Kartika-1 & $0,12 \mathrm{bc}$ & $0,15 \mathrm{abc}$ \\
Kayumas & $0,06 \mathrm{e}$ & $0,19 \mathrm{a}$ \\
Sigararutang & $0,16 \mathrm{ab}$ & $0,13 \mathrm{abc}$ \\
\hline
\end{tabular}

Keterangan: Angka yang diikuti oleh huruf yang berbeda pada kolom yang sama menunjukkan hasil yang berbeda nyata menurut Uji Jarak Berganda Duncan taraf 5\%. 
Tabel 4. Koefisien korelasi karakter pertumbuhan dan perakaran bibit kopi

\begin{tabular}{|c|c|c|c|c|c|c|c|c|c|c|c|c|}
\hline & TT & DB & JD & $\begin{array}{l}\text { BS } \\
\text { Pucuk }\end{array}$ & $\begin{array}{l}\text { BK } \\
\text { Pucuk }\end{array}$ & $\begin{array}{l}\text { BS } \\
\text { AT }\end{array}$ & BK AT & $\begin{array}{l}\text { BS } \\
\mathrm{AL}\end{array}$ & $\begin{array}{l}B K \\
A L\end{array}$ & PA & BA & NAP \\
\hline TT & 1,00 & & & & & & & & & & & \\
\hline DB & 0,89 & 1,00 & & & & & & & & & & \\
\hline JD & 0,65 & 0,77 & 1,00 & & & & & & & & & \\
\hline BS Pucuk & 0,75 & 0,80 & 0,89 & 1,00 & & & & & & & & \\
\hline BK Pucuk & 0,80 & 0,87 & 0,90 & 0,99 & 1,00 & & & & & & & \\
\hline BS AT & 0,85 & 0,90 & 0,73 & 0,84 & 0,89 & 1,00 & & & & & & \\
\hline BK AT & 0,87 & 0,91 & 0,67 & 0,81 & 0,86 & 0,98 & 1,00 & & & & & \\
\hline BS AL & 0,57 & 0,61 & 0,89 & 0,93 & 0,88 & 0,64 & 0,57 & 1,00 & & & & \\
\hline BK AL & 0,56 & 0,71 & 0,85 & 0,91 & 0,89 & 0,74 & 0,71 & 0,91 & 1,00 & & & \\
\hline PA & 0,79 & 0,77 & 0,83 & 0,89 & 0,87 & 0,77 & 0,73 & 0,81 & 0,74 & 1,00 & & \\
\hline BA & 0,78 & 0,88 & 0,82 & 0,93 & 0,95 & 0,94 & 0,93 & 0,79 & 0,91 & 0,79 & 1,00 & \\
\hline NAP & $-0,01$ & $-0,08$ & $-0,31$ & $-0,09$ & $-0,13$ & 0,07 & 0,16 & $-0,13$ & 0,10 & $-0,11$ & 0,14 & 1,00 \\
\hline
\end{tabular}

Keterangan: $\mathrm{TT}$ =tinggi tanaman, $\mathrm{DB}=$ diameter batang, JD=jumlah daun, $\mathrm{BS}=$ bobot segar, $\mathrm{BK}=$ bobot kering, $\mathrm{AT}=\mathrm{akar}$ tunggang, $\mathrm{AL}=$ akar lateral, $\mathrm{PA}=$ panjang akar, $\mathrm{BA}=$ biomassa akar, $\mathrm{NAP}=$ nisbah akar pucuk.

Adanya perbedaan morfologi akar pada varietas kopi yang diuji dipengaruhi respons genetik dari setiap varietas terhadap kondisi lingkungan tempat tumbuh. Sistem perakaran yang baik (ditandai dengan nilai panjang akar; biomassa akar; nisbah akar tajuk yang tinggi) akan membuat daya jelajah akar lebih luas sehingga tanaman masih dapat bertahan hidup meskipun kondisi lingkungan sekitarnya tercekam. Akar sangat penting berperan sebagai sensor dari banyak kondisi lingkungan seperti kekeringan, pemadatan tanah, atau genangan air (Silveira et al. 2014).

\section{Korelasi antara karakter pertumbuhan dan perakaran bibit kopi}

Bobot segar dan kering akar tunggang, panjang akar, dan biomassa akar bibit kopi berkorelasi positif dengan tinggi tanaman, diameter batang, jumlah daun, bobot segar dan bobot kering pucuk. Bobot segar dan bobot kering akar tunggang berkorelasi positif sangat kuat $(>0,8)$ terhadap tinggi tanaman dan diameter batang. Panjang akar berkorelasi sangat kuat terhadap jumlah daun, bobot segar, dan bobot kering pucuk. Biomassa akar berkorelasi sangat kuat terhadap diameter batang, jumlah daun, bobot pucuk segar, dan bobot pucuk kering. Nisbah akar pucuk berkorelasi negatif dengan karakter pertumbuhan pucuk namun nilai koefisiennya sangat rendah $(<0,2)$.

Karakter perakaran bibit kopi Arabika yang diamati mempunyai nilai koefisien korelasi tinggi terhadap karakter pertumbuhan bibit $(>0,6)$. Semakin tinggi nilai koefisien korelasi diantara variabel pengamatan maka hubungan antar variabel tersebut semakin kuat (Sugiyono 2011). Salah satu contohnya adalah panjang akar mempunyai nilai koefisien korelasi positif dengan tinggi tanaman sebesar 0,79 . Hal ini menunjukkan bahwa pertumbuhan akar yang semakin panjang akan diikuti oleh pertumbuhan bibit yang semakin tinggi. Jika bibit kopi Arabika mempunyai pertumbuhan dan perkembangan akar yang kuat maka bibit tersebut juga mempunyai pertumbuhan pucuk yang vigor. Varietas kopi Arabika BLP-4 dan Sigararutang mempunyai perkembangan akar yang baik sehingga pertumbuhan pucuk kedua varietas tersebut juga bagus.

\section{KESIMPULAN}

Masing-masing varietas memiliki karakter pertanaman yang berbeda. Varietas BLP-4 dan Sigararutang mempunyai perakaran paling baik. Varietas BLP-4 mempunyai nilai tinggi tanaman, diameter batang, bobot segar akar tunggang, bobot kering akar tunggang, dan biomassa akar paling besar. Jumlah daun terbanyak dimiliki oleh varietas Gayo-1. Nilai bobot segar pucuk, bobot kering pucuk, bobot segar akar lateral, dan panjang akar terbesar ditunjukkan oleh varietas Sigararutang. Varietas BLP-4, Gayo-1, dan Sigararutang merupakan varietas kopi Arabika yang berpotensi mempunyai daya adaptasi luas. Perlu dilakukan penelitian lanjutan pada ketiga varietas tersebut dengan memodifikasi kondisi media yang tercekam abiotik untuk membuktikan hipotesis tersebut.

\section{DAFTAR PUSTAKA}

Anasari NR, Kendarini N, Purnamaningsih SL. 2017. Interaksi genotip $x$ lingkungan pada empat genotip pakchoy (Brassica rapa L.) di tiga lokasi. J Prod Tan. 5(1):54-60.

Andarini YN, Afza H, Herlina L, Sutoro. 2017. Evaluasi plasma nutfah padi gogo berdasarkan karakter kuantitatif perakaran tanaman. Bul Plasma Nutfah. 23(1):33-40. https://dx.doi.org/10.21082/blpn.v23n1.2017.p33-40.

Betegon-Putze I, Gonzalez A, Sevillano X, BlascoEscamez D, Cano-Delgado Al. 2019. MyROOT: a method and software for the semiautomatic measurement of primary root length in Arabidopsis seedlings. Plant J. 98(6):1145-1156. https://dx.doi.org/10.1111/tpj.14297. 
Dahlan Z, Sarno S, Barokah A. 2009. Model Arsitektur Akar Lateral dan Akar Tunjang Bakau (Rhizophora apiculata Blume.). J Penelit Sains. 12(2):1-6.

Da Rosa SDVF, McDonald MB, Veiga AD, Vilela F de L, Ferreira IA. 2010. Staging coffee seedling growth: a rationale for shortening the coffee seed germination test. Seed Sci Technol. 38(2):421-431. https://dx.doi.org/10.15258/sst.2010.38.2.15.

Defrenet E, Roupsard O, Van den Meersche K, Charbonnier F, Pastor Pérez-Molina J, Khac E, Prieto I, Stokes A, Roumet C, Rapidel B, et al. 2016. Root biomass, turnover and net primary productivity of a coffee agroforestry system in Costa Rica: effects of soil depth, shade trees, distance to row and coffee age. Ann Bot. 118(4):833-851. https://dx.doi.org/10.1093/aob/mcw153.

Delory BM, Weidlich EWA, Meder L, Lütje A, Duijnen R, Weidlich R, Temperton VM. 2017. Accuracy and bias of methods used for root length measurements in functional root research. Börger $\mathrm{L}$, editors. Methods Ecol Evol. 8(11):1594-1606. https://dx.doi.org/10.1111/2041-210X.12771.

Erdiansyah NP, Wachjar A, Sulistyono E, Supijatno S. 2019. Growth Response of Seedlings of Four Robusta Coffee (Coffea canephora Pierre. Ex. A. Froehner) Clones to Drought Stress. Pelita Perkeb (Coffee Cocoa Res J). 35(1):1-11. https://dx.doi.org/10.22302/iccri.jur.pelitaperkebunan .v35i1.344.

Gaiser T, Perkons U, Küpper PM, Kautz T, UteauPuschmann D, Ewert F, Enders A, Krauss G. 2013. Modeling biopore effects on root growth and biomass production on soils with pronounced sub-soil clay accumulation. Ecol Model. 256:6-15. https://dx.doi.org/10.1016/j.ecolmodel.2013.02.016.

Gichimu BM, Cheserek JJ, Mushimiyamana D, King'oro MW. 2014. Effect of Different Watering Regimes on Agro-morphology of Selected Coffee Genotypes. Am J Exp Agric. 4(9):1016-1026. https://dx.doi.org/10.9734/AJEA/2014/9187.

Himmelbauer ML, Loiskandl W, Kastanek F. 2004. Estimating length, average diameter and surface area of roots using two different image analyses systems. Plant Soil. 260(1/2):111-120. https://dx.doi.org/10.1023/B:PLSO.0000030171.288 21.55.

Judd L, Jackson B, Fonteno W. 2015. Advancements in root growth measurement technologies and observation capabilities for container-grown plants. Plants. 4(3):369392. https://dx.doi.org/10.3390/plants4030369.

Kakanga CJR, Nio SA, Siahaan P. 2017. Rasio akar: tajuk tanaman padi lokal Sulawesi Utara yang mengalami cekaman banjir dan kekeringan pada fase vegetatif (Root: shoot ratio of North Sulawesi local rice under waterlogging and drought at the vegetative phase). J Bios Logos. 7(1):17-21. https://dx.doi.org/10.35799/jbl.7.1.2017.16208.

Komala CA, Kuwato E. 2008. Evaluasi kualitas bibit kemenyan durame (Styrax benzoin Dryland) umur 3 bulan. Info Hutan. 5(4):337-345.
Kufa T, Burkhardt J. 2013. Studies on root growth of Coffea arabica populations and its implication for sustainable management of natural forests. J Agric Crop Res. 1(1):1-9.

Lewu LD, Killa YM. 2020. Keragaman perakaran, tajuk serta korelasi terhadap hasil kedelai pada berbagai kombinasi interval penyiraman dan dosis bahan organik. Perbal J Pertan Berkelanjutan. 8(3):114121.

Partelli FL, Cavalcanti AC, Menegardo C, Covre AM, Gontijo I, Braun H. 2020. Spatial distribution of the root system of Conilon and Arabica coffee plants. Pesqui Agropecuária Bras. 55:1-9. https://dx.doi.org/10.1590/s1678-3921.pab2020.v55.01333.

Parwata IGMA, Santoso BB, Soemeinaboedhy IN. 2017. Pertumbuhan dan distribusi akar tanaman muda beberapa genotipe unggul jarak pagar (Jatropha curcas L.). J Sains Teknol Lingkung. 3(2):9-17. https://dx.doi.org/10.29303/jstl.v3i2.24.

Plecher H. 2020. Average prices for Arabica and robusta coffee worldwide from 2014 to 2025. Statista; [Diakses $15 \quad$ Oktober 2020]. https://www.statista.com/statistics/675807/averageprices-arabica-and-robusta-coffee-worldwide/.

Rodriguez WDM, Pego Evangelista AW, Junior JA, Honorato MV. 2017. Growing of coffee seedlings on different substrates and fertilized with lithothamium. Rev Fac Nac Agron. 70(2):8177-8182. https://dx.doi.org/10.15446/rfna.v70n2.64522.

Sakai E, Barbosa EAA, Silveira JMC, Pires RCM. 2015. Coffee productivity and root system in cultivation schemes with different population arrangements and with and without drip irrigation. Agric Water Manag. 148:1623. https://dx.doi.org/10.1016/j.agwat.2014.08.020.

Silva EA, Silva SHG, Oliveira GC, Carducci CE. 2016. Root spatial distribution in coffee plants of different ages under conservation management system. Afr J Agric Res. 11(49):4970-4978. https://dx.doi.org/10.5897/AJAR2016.11356.

Silveira HR de O, Santos MDO, Alves JD, Souza KRD de, Andrade CA, Alves RGM. 2014. Growth effects of water excess on coffee seedlings (Coffea arabica L.). Acta Sci Agron. 36(2):211-218. https://dx.doi.org/10.4025/actasciagron.v36i2.17557.

Sugiyono. 2011. Metodologi penelitian kuantitatif kualitatif dan R\&D. Bandung (ID): Alfabeta.

Syahadat RM, Aziz SA. 2013. Hubungan jumlah bunga, jumlah daun, jumlah anak daun, jumlah cabang, dan tinggi tanaman terhadap pertumbuhan bibit tanaman kemuning (Murraya paniculata (L.) Jack). J Lanskap Indones. 5(1):23-25.

Torey PC, Song Ai N, Siahaan P, Mambu SM. 2013. Karakter morfologi akar sebagai indikator kekurangan air pada padi lokal Superwin. J Bios Logos 3(2):57-64.

Vicente MR, Mantovani EC, Fernandes ALT, Neves JCL, Figueredo EM, Delazari FT. 2017. Spacial distribution of fertigated coffee root system. Ciencia e Agrotecnologia 41(1):72-80. https://dx.doi.org/10.1590/1413-70542016411021316. 
Wibowo A. 2019. Potensi dan tantangan kopi di era milenial. War Pus Penelit Kopi Kakao Indones. 31(2):16-23.

Wintgens JN, editor. 2004. Coffee: growing, processing, sustainable production. A guidebook for growers, processors, traders, and researchers. Jerman: WILEY-VCH Verlag GmbH \& Co. KGaA.
Zakariyya F. 2017. Karakter morfologi perakaran beberapa semaian klon kakao asal biji. In: AGROPROSS National Conference Proceedings of Agriculture. Jember (ID): Jurusan Produksi Pertanian, Politeknik Negeri Jember. 